Research article Open Access

\title{
BRCA1 and BRCA2 mutation predictions using the BOADICEA and BRCAPRO models and penetrance estimation in high-risk French-Canadian families
}

\author{
Antonis C Antoniou1, Francine Durocher ${ }^{2}$, Paula Smith1, Jacques Simard², INHERIT BRCAs \\ program members $^{3}$ and Douglas F Easton ${ }^{1}$
}

\begin{abstract}
${ }^{1}$ Cancer Research UK Genetic Epidemiology Unit, Strangeways Research Laboratory, Department of Public Health and Primary Care, University of Cambridge, Cambridge, UK

${ }^{2}$ Cancer Genomics Laboratory, Oncology and Molecular Endocrinology Research Center, Centre Hospitalier, Universitaire de Québec and Laval University, Québec, Canada

${ }^{3}$ Other members of the INHERIT (INterdisciplinary HEalth Research International Team on BReast CAncer susceptibility) BRCAs involved in clinical aspects of the program are listed in the Acknowledgments section
\end{abstract}

Corresponding author: Antonis C Antoniou, antonis@srl.cam.ac.uk

Received: 5 Sep 2005 Revisions requested: 12 Oct 2005 Revisions received: 7 Nov 2005 Accepted: 9 Nov 2005 Published: 12 Dec 2005

Breast Cancer Research 2006, 8:R3 (doi:10.1186/bcr1365)

This article is online at: http://breast-cancer-research.com/content/8/1/R3

(C) 2005 Antoniou, et al.; licensee BioMed Central Ltd.

This is an open access article distributed under the terms of the Creative Commons Attribution License (http://creativecommons.org/licenses/by/2.0), which permits unrestricted use, distribution, and reproduction in any medium, provided the original work is properly cited.

\begin{abstract}
Introduction Several genetic risk models for breast and ovarian cancer have been developed, but their applicability to specific populations has not been evaluated. We used data from FrenchCanadian families to evaluate the mutation predictions given by the BRCAPRO and BOADICEA models. We also used this data set to estimate the age-specific risks for breast and ovarian cancer in BRCA1 and BRCA2 mutation carriers.

Methods A total of 195 families with multiple affected individuals with breast or ovarian cancer were recruited through the INHERIT (INterdisciplinary HEalth Research International Team on BReast CAncer susceptibility) BRCAs research program. Observed $B R C A 1$ and BRCA2 mutation status was compared with predicted carrier probabilities under the BOADICEA and BRCAPRO models. The models were assessed using Brier scores, attributes diagrams and receiver operating characteristic curves. Log relative risks for breast and ovarian cancer in mutation carriers versus population risks were estimated by maximum likelihood, using a modified segregation analysis implemented in the computer program MENDEL. Twenty-five families were eligible for inclusion in the BRCA1 penetrance analysis and 27 families were eligible for the $B R C A 2$ penetrance analysis.
\end{abstract}

Results The BOADICEA model predicted accurately the number of $B R C A 1$ and $B R C A 2$ mutations for the various groups of families, and was found to discriminate well at the individual level between carriers and noncarriers. BRCAPRO over-predicted the number of mutations in almost all groups of families, in particular the number of BRCA1 mutations. It significantly overestimated the carrier frequency for high predicted probabilities. However, it discriminated well between carriers and noncarriers. Receiver operating characteristic (ROC) curves indicate similar sensitivity and specificity for BRCAPRO and BOADICEA. The estimated risks for breast and ovarian cancer in BRCA1 and BRCA2 mutation carriers were consistent with previously published estimates.

Conclusion The BOADICEA model predicts accurately the carrier probabilities in French-Canadian families and may be used for counselling in this population. None of the penetrance estimates was significantly different from previous estimates, suggesting that previous estimates may be appropriate for counselling in this population.

\section{Introduction}

$B R C A 1$ and $B R C A 2$ are the most important breast cancer susceptibility genes identified to date. A recent meta-analysis of 22 population-based studies of breast and ovarian cancer

BOADICEA = Breast and Ovarian Analysis of Disease Incidence and Carrier Estimation Algorithm; BS = Brier score; Cl = confidence interval; INHERIT = INterdisciplinary Health Research International Team; $\mathrm{NCI}=$ National Cancer Institute; ROC = receiver operating characteristic; VUS = variants of unspecified significance. 
[1] estimated the risk for breast cancer by age 70 years in $B R C A 1$ and BRCA2 carriers to be $65 \%$ and $45 \%$, respectively. The corresponding ovarian cancer risks were $39 \%$ and $9 \%$, respectively. A number of other studies have investigated the penetrance of these mutations, and risks have been found to vary by birth cohort, mutation position in the gene, ascertainment criteria and population studied [1-13]. Having precise estimates of these risks is important for counselling mutation carriers, and such estimates are fundamental components of cancer risk prediction models. Such models are currently being used and developed for counselling high risk women in clinical genetics centres [14-17].

Population isolates or founder populations provide a particular challenge for risk models, because the frequency of mutations may be altered by the occurrence of specific founder mutations that may attain relatively high frequency. Notable examples of this are the founder BRCA1 and BRCA2 mutations in the Ashkenazi Jewish population, and the founder BRCA2 population in Iceland $[13,18-20]$. The French-Canadian population is an example of such a founder population. The province of Quebec population includes about 6 million French-Canadians, who are descendants of about 10,000 immigrants, mostly from France, who settled in Nouvelle France between 1608 and 1760. Altogether, approximately $80 \%$ of these founders still have descendants in Quebec today, and they account for the major part of the contemporary French-Canadian gene pool $[21,22]$. Founder mutations in both BRCA1 and $B R C A 2$ genes have been characterized in French-Canadian high-risk breast/ovarian cancer families [23-26].

A number of models that predict $B R C A 1$ and $B R C A 2$ mutation carrier risks and/or breast and ovarian cancer risks have been reported in the literature [14-16,27-29]. The BRCAPRO model was developed using published data and assumes that genetic susceptibility to breast and ovarian cancer is due to mutations in BRCA1 and BRCA2. The program uses information on first-degree and second-degree relatives to compute the probability that an individual carries a mutation in these genes $[16,30]$. The recently published BOADICEA (Breast and Ovarian Analysis of Disease Incidence and Carrier Estimation Algorithm) model was developed using a combination of population-based families and families with multiple affected individuals, mainly from the UK. It takes into account the simultaneous effects of BRCA1, BRCA2 and the residual familial clustering of breast cancer not accounted by these genes, which is assumed to be explained by a polygenic model [14] The model can be used to compute age-specific cancer risks and mutation carrier probabilities using information on breast and ovarian cancer occurrence in families of any size or structure.

In the present study we used data from families of FrenchCanadian origin identified through the INHERIT (INterdisciplinary HEalth Research International Team on BReast CAncer susceptibility) BRCAs integrated clinical research program to assess the BRCAPRO and BOADICEA models of genetic susceptibility to breast cancer $[14,16]$ and to investigate whether these models are suitable for counselling women in this population. We also used this data set to estimate the risks for breast and ovarian cancer conferred by $B R C A 1$ and BRCA2 mutations.

\section{Materials and methods Ascertainment of families}

High-risk French-Canadian breast and/or ovarian families were recruited into a research project started in 1996, which subsequently evolved into a large ongoing interdisciplinary research program designated INHERIT BRCAs [31,32]. A major component was to identify and characterize $B R C A 1$ and BRCA2 mutations in the French-Canadian population. This integrated clinical research program was composed of a network of referring clinicians across the province of Quebec.

Following pre-test education sessions and detailed analysis of familial history, individuals were recruited if their family met one or more of the following strict criteria: the family had at least four individuals with breast and/or ovarian cancer diagnosed at any age in first-degree or second-degree relatives; the family had three first-degree relatives affected with breast and/or ovarian cancer at any age; or the family carried a deleterious mutation already identified in the BRCA1 or BRCA2 genes. Eight additional families that did not meet those strict criteria were recruited when the analysis of pedigrees was suggestive of a genetic component (e.g. monozygotic twins affected with breast cancer at an early age; four related individuals with early-onset breast cancer; one case of male breast cancer plus a woman affected with early breast cancer). All participants had to be at least 18 years of age and mentally competent. In most instances, the diagnoses of breast and/or ovarian cancer were confirmed by examining a pathology report. Clinicians involved in the research program were responsible for disclosure of the BRCA1/BRCA2 test result to participants. Approval was obtained from eight ethics committees corresponding to the various institutions participating in the research program.

A total of 191 families were recruited before 1 January 2003, and data from these families were used to assess the ability of the models to predict $B R C A 1$ and BRCA2 carrier probabilities. Four additional families ascertained by July 2003 were found to segregate $B R C A 1$ and $B R C A 2$ truncating mutations and were included in the analyses to estimate penetrance, in order to improve the precision of the penetrance estimates.

\section{Mutation testing}

Individuals were assumed to be $B R C A 1$ or $B R C A 2$ positive only if they carried a clearly deleterious mutation. Carriers of variants of unspecified significance (VUS) were assumed to 
be BRCA1/BRCA2 negative for the purpose of these analyses.

Once a signed informed consent form had been obtained from each participant, $40 \mathrm{ml}$ blood was drawn and genomic DNA extracted using the guanidine hydrochloride-proteinase $k$ method [33] and the QIAmp Maxi blood kit (QIAGEN, Mississauga, Canada), in accordance with the manufacturer's instructions. Participants from families considered in the present study were first tested for a panel of 18 truncating mutations detected or reported in the French-Canadian population. This screening led to the discovery of mutations in 52 families (seven distinct mutations), which accounted for $88 \%$ of all positive families identified before July 2003. DNA samples from at least one individual from 113 of the families with inconclusive $B R C A 1 / B R C A 2$ test results (i.e. no mutation found in the first stage) were sent to Myriad Genetics Laboratories (Salt Lake City, UT, USA) for full-length BRCA1/ $B R C A 2$ sequencing using their Comprehensive BRACAnaly$\operatorname{sis}^{\circledR}$. No additional analysis was performed for 30 families. Testing services were performed according to the Memorandum of Understanding of the US National Cancer Institute $(\mathrm{NCl})$ for $\mathrm{NCl}$-funded research testing services for $B R C A 1$ and BRCA2 (project no. NCl 173). This second step screening approach led to the discovery of mutations in seven different families (seven distinct mutations), leaving 106 families with an inconclusive result [24]. DNA samples from 98 families with an inconclusive result were tested at the Cancer Genomics Laboratory at Québec City by multiplex ligation probe amplification. These approaches failed to detect any deleterious rearrangement (Moisan AM, Fortin J, Dumont M, Samson C, Bessette $P$, Chiquette J, Laframboise R, Lépine J, Lespérance B, Pichette R, Plante M, Provencher L, Voyer P, Goldgar D, Bridge P, Simard J. No evidence of BRCA1/2 genomic rearrangements in high risk French-Canadian breast/ ovarian cancer families, submitted, 2005). A confirmation test was performed for each individual belonging to a BRCA1/ BRCA2 positive family on a second blood sample by the Molecular Diagnostic Laboratory of Alberta Children's Hospital (Calgary, Alberta, Canada), under the responsibility of Dr Peter Bridge. VUS were detected in 13 families without deleterious mutations.

\section{Statistical methods}

\section{Penetrance estimation}

We used data from the families in which deleterious $B R C A 1$ or BRCA2 mutations were identified to estimate the breast and ovarian cancer risks in carriers of such mutations. For these calculations we considered only those families in which at least one mutation carrier was identified and at least one further family member had DNA testing after the mutation carrier was identified. BRCA1 and BRCA2 families in which no member was tested for mutations subsequent to the first identified carrier were excluded (seven families). Twenty-five families segregating BRCA1 mutations and 27 families segregating
BRCA2 mutations were eligible for inclusion in the analysis. We used information on the mutation status and disease occurrence in the family members to estimate the breast and ovarian cancer incidence rates in mutation carriers. We used the information available before 2003, with the exception of information about four eligible families segregating a deleterious $B R C A 1 / B R C A 2$ mutation, which were recruited by July 2003.

The parameters were estimated by maximum likelihood using a modified segregation analysis implemented in the computer program MENDEL [34]. We assumed a model in which a female after birth was at risk for developing breast or ovarian cancer, or was censored at death or the age at which she was last observed. The disease incidence rates were assumed to depend on the underlying genotype through a Cox proportional hazards model $\lambda_{i}(t)=\lambda_{0}(t) R H(t)$, where $\lambda_{0}(t)$ is the baseline incidence rate for noncarriers and $\mathrm{RH}(\mathrm{t})$ is the relative hazard at age $t$ for carriers compared with noncarriers.

Nonmutation carriers were assumed to be susceptible to the population incidence rates for Quebec during 1978-1981 (International Agency for Research on Cancer, Cancer Incidence in Five Continents, Volume V, IARC Scientific publications, Lyon, 1987). The models were parameterized in terms of the age-specific log relative hazard for breast and ovarian cancer compared with the population risks. More details on this method can be found in the report by Antoniou and coworkers [1]. We also performed analyses in which the end-point of interest was either breast or ovarian cancer. A single set of incidence rates was derived representing the incidence of either breast or ovarian cancer in BRCA1 or BRCA2 mutation carriers. All analyses were performed separately for the $B R C A 1$ and BRCA2 positive families.

To correct for ascertainment, we employed the sequential ascertainment correction scheme described by Cannings and Thompson [35]. Because family ascertainment was through multiple affected individuals with at least one family member testing positive for mutations, we maximized the conditional likelihood of all phenotypic and genotypic information in the family given all disease phenotypes and the genotypic information up to the point at which the first mutation carrier was identified.

\section{BRCA1 and BRCA2 carrier probabilities}

To assess the consistency of the Quebec families with genetic models that incorporate the effects of BRCA1 and BRCA2 mutations, we used the data to estimate the BRCA1 and $B R C A 2$ mutation carrier probabilities of the first screened individual in each family. For this analysis we used data from the 191 families recruited between 1996 and 2003, and considered only those families in which mutation screening was carried out in at least one family member. The families of individuals who were recruited because of prior knowledge of 
Table 1

Summary statistics for the $\mathbf{1 8 8}$ families used in predicting the mutation status of the first screened individual

\begin{tabular}{lcc}
\hline & Full pedigrees & First- and second-degree relatives only \\
\hline Mean number of individuals per family & 27.9 & 15.9 \\
Number of BC cases & 993 & 612 \\
Number of OC cases & 66 & 54 \\
Number of bilateral BC cases & 70 & 58 \\
Cases with BC and OC & 26 & 12 \\
Number of male BC cases & 19 & 11 \\
Median age at BC diagnosis (years) & 51 & 51 \\
Median age at OC diagnosis (years) & 57 & 58 \\
\hline
\end{tabular}

aCorresponds to females only. BC, breast cancer; OC, ovarian cancer.

$\mathrm{BC}$, breast cancer; OC, ovarian cancer.

a mutation segregating within the family were excluded (three in total), thus leaving a total of 188 families. For the purpose of these predictions, the first individual in whom mutation screening was carried out was considered the proband, and predictions were only made for these individuals. In some instances a mutation was identified after screening several individuals in the family, even though the first tested individual was found to be a noncarrier. These subsequent rounds of testing were ignored, because the predicted probabilities for subsequent individuals would be altered by the fact that a mutation had not been found previously. We used the information on breast and ovarian cancer diagnosis in families that was available before 2003.

\section{Mutation prediction models}

BOADICEA is a computerized risk assessment program that can be used to compute the probability of detecting a BRCA1 or BRCA2 mutation and the risks for developing breast or ovarian cancer [14]. The model considers the occurrence of breast and ovarian cancer within the family. In the current version, only the first cancer in an individual is considered. Disease occurrence in males and cancers other than breast and ovarian cancers are ignored. The model is a genetic model that is implemented in the program MENDEL [34], so that families of any size or structure can be included. In the model, BRCA1 mutations are assumed to have a population allele frequency of $0.06 \%$ and BRCA2 mutations to have an allele frequency of $0.10 \%$. The residual familial clustering not accounted for by $B R C A 1$ and $B R C A 2$ mutations is assumed to be explained by a polygenic model with a variance that decreases with increasing age [14]. We used an updated version of the model in which the cancer risks in both carriers and noncarriers also depend on the year of birth of the individual (Antoniou and coworkers, unpublished data). For example, the risk for breast cancer by age 70 years is $46 \%$ for a BRCA1 carrier born before 1920 , but it is $59 \%$ if the carrier is born after 1950 . For these analyses, the sensitivity of mutation detection was assumed to be $70 \%$ for BRCA1 and $80 \%$ for BRCA2 (Easton
D, based on Breast Cancer Linkage Consortium data; personal communication).

The BRCAPRO program computes the probability that an individual carries a $B R C A 1$ or a BRCA2 mutation based on information provided on relatives as distant as second degree $[16,36]$. The model assumes that genetic susceptibility to breast cancer is entirely due to mutations in BRCA1 and $B R C A 2$. We used the version implemented in the BayesMendel software, which is a library of programs written in the $\mathrm{R}$ programming environment [37,38]. BRCAPRO, as distributed in BayesMendel, comes with various options for BRCA1 and $B R C A 2$ penetrance and allele frequencies. For our purposes we assumed the non-Ashkenazi allele frequencies (BRCA1: 0.0006; and BRCA2: 0.00022). We also used the current default penetrances of BRCAPRO for populations other than Ashkenazi Jewish.

To provide a more direct comparison between the models, two sets of predictions were carried out under the BOADICEA model: taking into account the entire family as reported, which we refer to as 'full pedigrees'; and taking into account only the first-degree and second-degree relatives of the first screened individual.

\section{Model comparisons}

The models were calibrated by comparing the observed and expected numbers of mutations. The models were also evaluated in terms of the Brier score (BS) [39]. This is a measure of accuracy of the predictions that measures the total difference between observing a mutation and the predicted probability of detecting a mutation. This is defined as follows:

$B S=\frac{1}{n} \sum_{1}^{n}\left(p_{i}-x_{i}\right)^{2}$

Where $n$ is number of families, $p_{i}$ is the probability of detecting a $B R C A 1$ or $B R C A 2$ mutation, and $x_{i}$ is 0 if the proband was 
Table 2

\begin{tabular}{|c|c|c|c|c|}
\hline Cancer status & Model & $B R C A 1^{\mathrm{a}}$ & $B R C A 2^{\mathrm{a}}$ & Noncarriers \\
\hline \multirow[t]{5}{*}{ Unaffected } & Observed & 3 & 5 & 96 \\
\hline & BOADICEA & & & \\
\hline & Full pedigrees & 3.49 & 6.30 & 94.21 \\
\hline & Second-degree relatives & 2.46 & 4.10 & 97.44 \\
\hline & BRCAPRO & 10.74 & 4.20 & 89.06 \\
\hline \multirow[t]{5}{*}{ Breast cancer } & Observed & 6 & 12 & 55 \\
\hline & BOADICEA & & & \\
\hline & Full pedigrees & 8.68 & 13.17 & 51.14 \\
\hline & Second-degree relatives & 7.42 & 8.75 & 56.83 \\
\hline & BRCAPRO & 26.29 & 10.90 & 36.97 \\
\hline \multirow[t]{5}{*}{ Ovarian cancer } & Observed & 5 & 2 & 4 \\
\hline & BOADICEA & & & \\
\hline & Full pedigrees & 3.52 & 0.63 & 6.85 \\
\hline & Second-degree relatives & 2.27 & 0.41 & 8.31 \\
\hline & BRCAPRO & 5.12 & 0.56 & 5.32 \\
\hline \multirow[t]{5}{*}{ Totals } & Observed & 14 & 19 & 155 \\
\hline & BOADICEA & & & \\
\hline & Full pedigrees & 15.69 & 20.10 & 152.21 \\
\hline & Second-degree relatives & 12.15 & 13.26 & 162.59 \\
\hline & BRCAPRO & 42.16 & 15.67 & 130.35 \\
\hline
\end{tabular}

aNot mutually exclusive under BRCAPRO.

found not to carry a mutation and 1 if the proband was found to carry a $B R C A 1$ or BRCA2 mutation. The smaller the BS, the closer are the predictions to the observed data. The significance of the score was evaluated by the means of the Spiegelhalter z-statistic [40].

The models were also evaluated in terms of their ability to predict accurate probabilities (reliability), and the ability of the predictions to separate correctly the carriers and noncarriers (resolution/discrimination). These were assessed in terms of the attributes diagrams. This involved ranking the predicted probabilities and then dividing them into quantiles. The average predicted probability was computed for each quantile and this was then plotted against the observed mutation frequency in the quantile. Ninety-five per cent confidence intervals (Cls) for the observed frequencies were computed using a binomial distribution.

Receiver operating characteristic (ROC) curves were used to assess the specificity and sensitivity of the various models. Sensitivity here is defined as the proportion of tested individu- als with mutations with a detection or carrier probability higher than a given value (cutoff), and specificity is the proportion of individuals without mutations with a detection probability lower than the cutoff. The ROC curves plot the sensitivity against the specificity at all possible cutoffs and show the trade-off between the two measures. The area under the ROC curve is a measure of the accuracy of a model, such that the higher the area, the more accurate is the model (an area of 1 represents a perfect fit, and an area of 0.5 represents no predictive value).

\section{Results \\ BRCA1 and BRCA2 mutation prediction}

A total of 191 families were recruited before January 2003. Three of those families were recruited because of prior knowledge of a mutation segregating within the family and were therefore excluded from this analysis. Table 1 shows some summary statistics for these families. Ninety one percent of families were extended beyond second-degree relatives. In 104 families the first individual screened for mutations was unaffected, in 73 families the first screened individual had 
Table 3

Observed and expected number of mutations among the first screened individuals by number of cancers in the family

\begin{tabular}{|c|c|c|c|c|c|c|c|}
\hline \multirow[t]{2}{*}{ Number of cancers, age under 70 years } & \multirow[t]{2}{*}{ Model } & \multicolumn{2}{|c|}{$B R C A 1$} & \multicolumn{2}{|c|}{$B R C A 2$} & \multicolumn{2}{|c|}{ Noncarriers } \\
\hline & & Observed & Expected & Observed & Expected & Observed & Expected \\
\hline \multirow[t]{4}{*}{$\geq 3 \mathrm{BC}, \geq 1 \mathrm{OC}$} & BOADICEA & & & & & & \\
\hline & Full pedigrees & 9 & 6.92 & 4 & 3.80 & 21 & 23.28 \\
\hline & Second-degree relatives & 6 & 3.12 & 1 & 1.49 & 7 & 9.38 \\
\hline & BRCAPRO & 6 & 7.80 & 1 & 2.35 & 7 & 3.98 \\
\hline \multirow[t]{4}{*}{$\geq 4 \mathrm{BC}, 0 \mathrm{OC}$} & BOADICEA & & & & & & \\
\hline & Full pedigrees & 2 & 6.20 & 14 & 14.75 & 90 & 85.05 \\
\hline & Second-degree relatives & 2 & 4.11 & 12 & 8.60 & 57 & 58.29 \\
\hline & BRCAPRO & 2 & 19.40 & 12 & 8.27 & 57 & 43.37 \\
\hline \multirow[t]{4}{*}{$3 \mathrm{BC}, 0 \mathrm{OC}$} & BOADICEA & & & & & & \\
\hline & Full pedigrees & 0 & 0.82 & 1 & 1.20 & 25 & 23.97 \\
\hline & Second-degree relatives & 1 & 1.09 & 2 & 1.77 & 37 & 37.13 \\
\hline & BRCAPRO & 1 & 5.43 & 2 & 2.97 & 37 & 31.60 \\
\hline \multirow[t]{4}{*}{$2 \mathrm{BC}$, any $\mathrm{OC}$} & BOADICEA & & & & & & \\
\hline & Full pedigrees & 3 & 1.75 & 0 & 0.34 & 19 & 19.91 \\
\hline & Second-degree relatives & 5 & 3.83 & 4 & 1.40 & 54 & 57.79 \\
\hline & BRCAPRO & 5 & 9.53 & 4 & 2.08 & 54 & 51.50 \\
\hline
\end{tabular}

$\mathrm{BC}$, breast cancer; OC, ovarian cancer.

developed breast cancer, and in the remaining 11 families the first screened individual had developed ovarian cancer. Table 2 shows the predicted number of mutations in those individuals under the BOADICEA and BRCAPRO models. As described in the Materials and methods section (above), BRCAPRO considers only second-degree relatives whereas BOADICEA allows for families of an arbitrary size and structure.

Among all the first screened individuals, 14 BRCA1 mutations and 19 BRCA2 mutations were identified. When information on all reported relatives in each family was considered, the total numbers of mutations predicted by BOADICEA were close to the observed numbers: 15.69 for $B R C A 1$ and 20.10 for $B R C A 2$. However, the expected number of BRCA1 mutations was somewhat lower than observed when only the second-degree relatives were considered (12.15) and much lower for BRCA2 (13.26 predicted versus 19 observed). BRCAPRO over-predicted the total number of BRCA1 mutations (42.16) and under-predicted the number of BRCA2 mutations (15.67). The Pearson $\chi^{2}$ goodness-of-fit test for comparing the total number of observed mutations with the predicted number was not significant for BOADICEA but was highly significant for BRCAPRO $\left(P=6 \times 10^{-6}\right)$. When information on all available relatives was used, the predicted numbers under BOADICEA were close to the observed numbers for both unaffected probands and among the breast and ovarian cancer patients. BRCAPRO over-predicted the number of $B R C A 1$ mutations among both unaffected individuals and breast cancer cases.

Table 3 shows the predicted number of mutations by the number of breast and ovarian cancer cases in the family diagnosed under age 70 years. The number of BRCA1 and BRCA2 mutations predicted by BOADICEA when the 'full pedigrees' were considered was close to the observed number in each subcategory except among families with four or more breast cancer cases, for which the number of predicted BRCA1 mutation was higher than the number observed (6.20 versus 2 ). When information on family members was restricted to the second-degree relatives of the first screened individual, the under-prediction of BRCA1 mutations was mainly among families with at least three cases of breast cancer and at least one case of ovarian cancer (3.12 expected versus 6 observed). The expected number of BRCA1 mutations was also somewhat higher than the observed number among families with at least four cases of breast cancer cases and no ovarian cancer cases (4.11 versus 2 ). The under-prediction of BRCA2 mutations was mainly within this category of families (8.60 expected versus 12 observed). BRCAPRO over-predicted the number of BRCA1 mutations in all categories, but especially among families with at least four breast cancer cases and no ovarian cancer cases (19.40 versus 2 ). Within the same family category, the number 
Attributes diagram

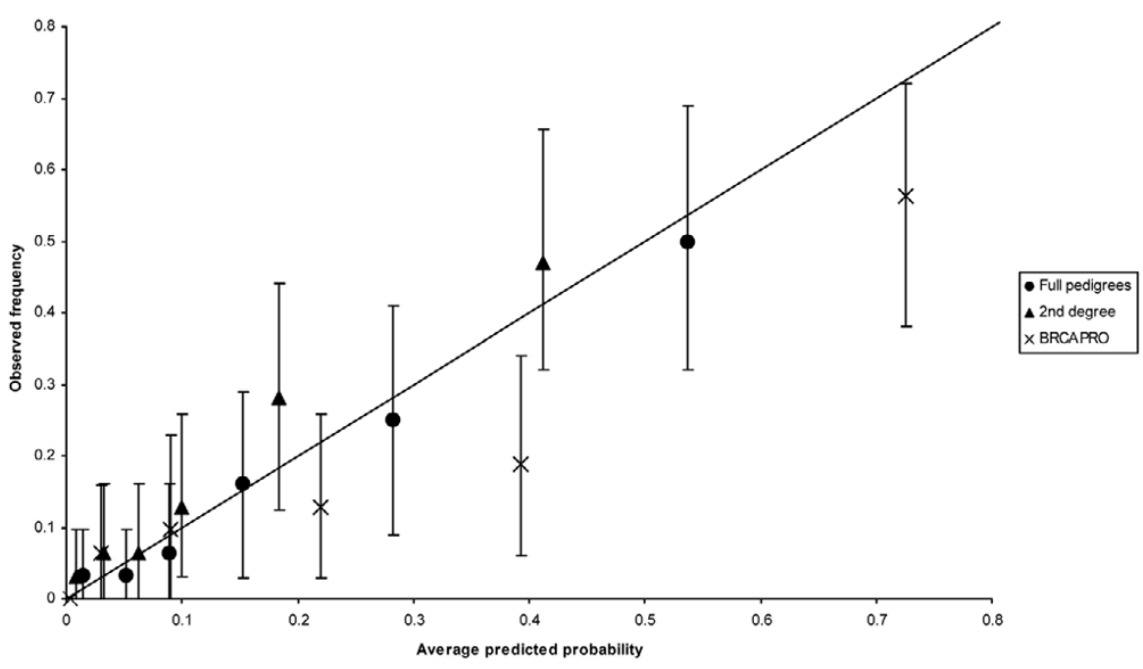

Attributes diagram. Shown is an attributes diagram comparing the predicted carrier probabilities and the observed carrier frequencies for $B R C A 1$ and BRCA2 mutations combined. BOADICEA predictions were carried out using data from all reported family members and restricted to seconddegree relatives only. BRCAPRO predictions were adjusted for an $80 \%$ sensitivity for the mutation screening methods used. Each point represents a sextile of the data and $95 \%$ confidence intervals were computed assuming a binomial distribution.

of BRCA2 mutations was under-predicted (8.27 expected versus 12 observed).

The BS for the probability of detecting a $B R C A 1$ or a $B R C A 2$ mutation under the BOADICEA model was 0.112 when data from the 'full pedigrees' were used to carry out the predictions and 0.118 when information was restricted to second-degree relatives only. The null hypothesis that the BOADICEA predictions are compatible with the observations was not rejected when the full pedigrees were used but was rejected when family history information was restricted to second-degree relatives only $(P=0.61$ and $P=0.02$, respectively, using Spiegelhalter's z-statistic). Under BRCAPRO the BS was $0.148(P=0.003)$.

\section{Resolution and reliability}

Figure 1 shows the attributes diagram for evaluating the reliability and resolution of the models. In this case the predicted carrier probabilities were ranked and divided into sextiles so that each quintile contains 31 or 32 observations. For this purpose the BRCAPRO carrier probabilities were multiplied by 0.80 to allow for reduced sensitivity of mutation testing (i.e. assuming that only $80 \%$ of the mutations could be identified with the screening methods used). Points on the $45^{\circ}$ line indicate both good reliability and resolution, whereas points above the line suggest that a model makes under-confident predictions and in effect provides poor discrimination and inaccurate probabilities. Points below the line suggest good discrimination but inaccurate probabilities.
The average predicted probability in each sextile was very close to the observed frequency under the BOADICEA model when the 'full pedigrees' were considered, indicating that under such circumstances the model discriminates between carriers and noncarriers and it gives accurate probabilities. When only the second-degree relatives were considered the average predicted probability was slightly lower than the observed frequency in each sextile, indicating somewhat lower discrimination. However, the $95 \%$ Cls of the observed frequencies for all sextiles include the average predicted probabilities. BRCAPRO provided very good discrimination between carriers and noncarriers, but it did not give accurate probabilities, especially at the two upper sextiles. In these cases the average predicted probabilities were much higher than the observed frequencies and outside their 95\% Cls.

The ROC curves under BOADICEA using the full pedigrees and under BRCAPRO are shown in Fig. 2. The area under the curve was 83\% (95\% Cl 75-91\%) under BRCAPRO and slightly lower, at $81 \%$ (95\% Cl 73-90\%), under BOADICEA. However, the difference was not statistically significant. The curves can be used to define cutoffs for referring individuals for BRCA1 and BRCA2 mutation screening. Under BOADI$\mathrm{CEA}$, if all individuals with mutation detection probability of $16 \%$ and over were referred for screening, a sensitivity of approximately $82 \%$ would be achieved. To obtain the same sensitivity under BRCAPRO, the mutation carrier probability cut-point needs to be approximately $25 \%$. At these cutoffs the BOADICEA predictions are $69 \%$ specific and the BRCAPRO predictions $64 \%$ specific. The positive predictive value of BOADICEA was $36 \%$ and the negative predictive value $95 \%$. 


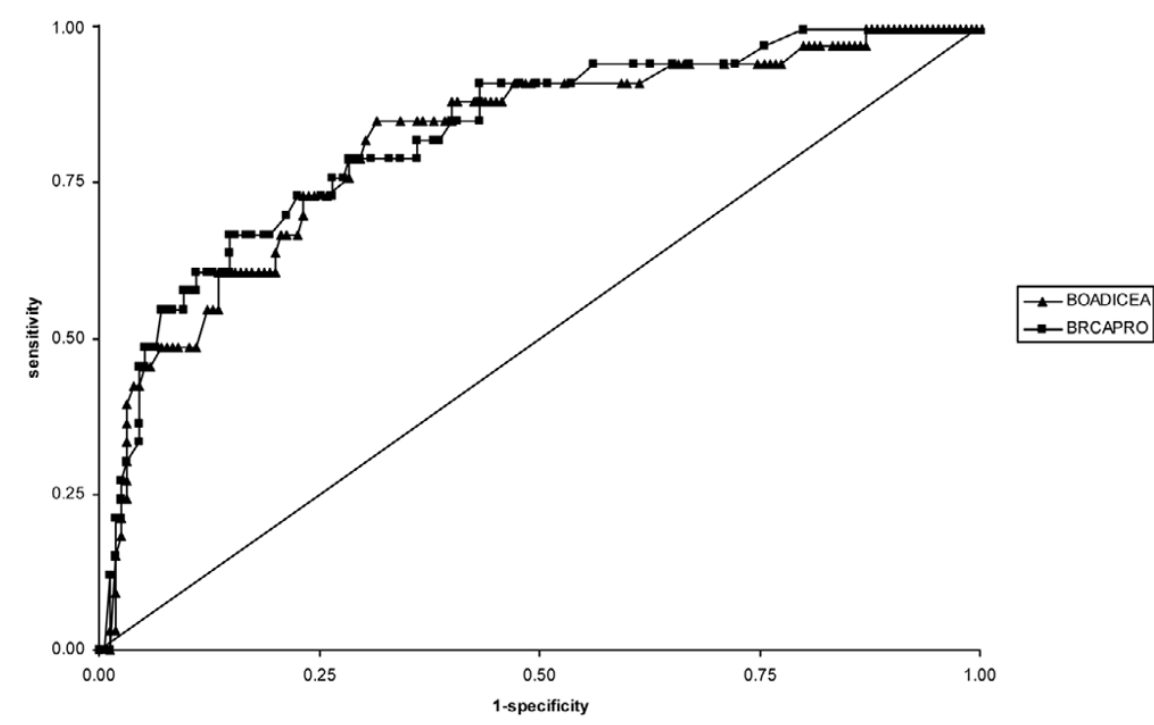

ROC curves. Shown are ROC curves for the BOADICEA and BRCAPRO predictions of carrying either a BRCA1 or a BRCA2 mutation. BOADICEA predictions assumed all reported family members. ROC, receiver operating characteristic.

Under BRCAPRO the positive predictive value was 32\% and the negative predictive value was $94 \%$. Carriers and noncarriers were correctly classified $72 \%$ and $67 \%$ of the time under BOADICEA and BRCAPRO, respectively.

\section{Risks for breast and ovarian cancers}

Table 4 shows the estimated cumulative risks for breast and ovarian cancer in BRCA1 and BRCA2 mutation carriers. The risks were estimated separately for $B R C A 1$ and $B R C A 2$ positive families. Twenty-five families were used in the BRCA1 analysis. The cumulative risk for breast cancer by age 50 years was estimated to be $20 \%$ (95\% Cl 0-45\%) and by age 70 years it was estimated to be $72 \%$ (95\% Cl 0-93\%). The corresponding ovarian cancer cumulative risks were estimated to be $1 \%(95 \% \mathrm{Cl} 0-10 \%)$ and 38\% (95\% Cl 0-78\%). When the event of interest was defined to be either breast or ovarian cancer, the cumulative risks for either cancer were estimated to be $23 \%$ by age 50 years $(95 \% \mathrm{Cl} 0-48 \%)$ and $83 \%$ by age 70 years $(95 \% \mathrm{Cl} 34-96 \%)$. When the analyses were restricted to the 18 families carrying the founder mutation R1443X, the cumulative risk for breast cancer was estimated to be $86 \%$ by age 70 years and the cumulative ovarian cancer risk $54 \%$.

Data from 27 families were used in the BRCA2 analyses. The cumulative risk for breast cancer was estimated to be $21 \%$ by age 50 years $(95 \% \mathrm{Cl} 0-55 \%)$ and $75 \%$ by age 70 years (95\% Cl 0-97\%). The corresponding cumulative risks for ovarian cancer were $0.4 \%(95 \% \mathrm{Cl} 0-2 \%)$ and $49 \%(95 \% \mathrm{Cl}$ $0-81 \%)$. The cumulative risk for developing either breast or ovarian cancer was estimated to be $35 \%$ by age 50 years (95\% $\mathrm{Cl} 0-64 \%)$ and $89 \%$ by age 70 years $(95 \% \mathrm{Cl} 34-$ $98 \%)$. When only the 23 families segregating the BRCA2 founder mutation 8765delAG were used, the cumulative breast cancer risk by age 70 was estimated to be $71 \%$ and the corresponding ovarian cancer cumulative risk to be $51 \%$.

\section{Discussion}

In the present study we used data from French-Canadian families included in the INHERIT program to evaluate the mutation risk prediction models BOADICEA and BRCAPRO $[14,16]$ and to estimate the breast and ovarian cancer risks conferred by $B R C A 1$ and BRCA2 mutations. A total of 157 of the families were screened for mutations using a three-step approach: screening for the 18 known French-Canadian mutations, full sequencing, and multiplex ligation probe amplification for detecting large rearrangements. Eight families were screened using only the first two steps and 30 families were only screened for the known French-Canadian mutations. However, the two additional steps detected only seven mutations, and it is therefore likely that no more than one or two mutations were missed.

Penetrance was estimated using data from families segregating BRCA1 and BRCA2 mutations. The breast cancer risk by age 70 years was estimated to be $72 \%$ in BRCA1 mutation carriers and $75 \%$ in BRCA2 mutation carriers. The corresponding ovarian cancer risks were $38 \%$ and $49 \%$, respectively. These point estimates are similar to the risks derived in previous studies conducted in families with multiple affected individuals $[2,3,41]$. However, our estimates are associated with very wide confidence intervals, and the present risks are also not significantly different from those derived using families identified through population-based series of breast or ovarian cancer patients $[1,4,6-8,42]$. The large confidence intervals are partly due to the relatively small number of mutation-posi- 
Table 4

\begin{tabular}{|c|c|c|c|c|c|c|}
\hline \multirow[t]{2}{*}{ Age (years) } & \multicolumn{3}{|c|}{$B R C A 1$} & \multicolumn{3}{|c|}{ BRCA2 } \\
\hline & $\mathrm{BC}$ & OC & $\mathrm{BC}$ or $\mathrm{OC}$ & $\mathrm{BC}$ & OC & $\mathrm{BC}$ or $\mathrm{OC}$ \\
\hline 30 & 3 & 0 & 4 & 0.3 & 0 & 0.4 \\
\hline 40 & 13 & 0 & 14 & 13 & 0.2 & 26 \\
\hline 50 & $20(0-45)$ & $1(0-10)$ & $23(0-48)$ & $21(0-55)$ & $0.4(0-2)$ & $35(0-64)$ \\
\hline 60 & 71 & 38 & 83 & 33 & 49 & 55 \\
\hline 70 & $72(0-93)$ & $38(0-78)$ & $83(34-96)$ & $75(0-97)$ & $49(0-81)$ & $89(34-98)$ \\
\hline
\end{tabular}

Shown are percentage cumulative risks ( $95 \%$ confidence interval). BC, breast cancer; OC, ovarian cancer.

tive families considered in the estimation ( 25 for $B R C A 1$ and 27 for $B R C A 2$ ) but most importantly are due to the strong ascertainment correction. In our analyses we conditioned on the phenotypes of all family members and the genotypes of all individuals up to and including the first identified mutation carrier in the family. Therefore, the information contributing to the analyses only came from individuals typed after the first mutation carrier was identified. The precision of these estimates may be improved by genotyping additional family members or by adding newly identified mutation-positive families in the analysis.

The BOADICEA and BRCAPRO genetic models for breast cancer susceptibility were used to compute expected numbers of mutations within subcategories of families. Empirical models such as the Myriad II model [29] and the Manchester scoring system [43] were used in these comparisons because they will be investigated in a future report (Simard and coworkers, unpublished data). The predicted numbers of mutations under BOADICEA were very close to the observed numbers when information on all reported relatives was taken into account. However, when only the second-degree relatives of the proband were considered the model under-predicted somewhat. This is consistent with the general principle that risk predictions should, where possible, take into account all known information.

The total number of mutations was significantly over-predicted by BRCAPRO. This was due to the over-prediction of BRCA1 mutations in almost all categories, with an under-prediction of the number of BRCA2 mutations. Even if the predicted number of mutations is adjusted for the reduced sensitivity of the mutation detection techniques used, BRCAPRO would still over-predict the number of BRCA1 mutations. The overprediction of $B R C A 1$ mutations does not seem to be due to the mutation frequency or penetrance estimates used in the models. The penetrance estimates used in the current implementation of BRCAPRO were the latest for non-Ashkenazi carriers, which are lower than the Breast Cancer Linkage Consortium estimates used in the initial implementation $[2,3]$ and are closer to the estimates used in BOADICEA, although they are not cohort specific. As implemented here, both BOADICEA and BRCAPRO use a BRCA1 mutation frequency of $0.06 \%$. BOADICEA uses a higher BRCA2 mutation frequency than does BRCAPRO (0.10\% versus $0.02 \%)$. However, when the BRCA2 frequency in BRCAPRO was assumed to be the same as in BOADICEA, BRCAPRO over-predicts the number of mutations for both BRCA1 and BRCA2 (predicted numbers: 29.42 and 38.18, respectively). Presumably, this discrepancy results from the fact that BRCAPRO does not model any of the residual familial clustering of breast cancer, other than BRCA1 or BRCA2, so that individuals with moderate family histories are assigned probabilities for being mutation carriers that are too high.

The Brier scores also indicate that BRCAPRO is not accurate in predicting individual carrier probabilities, whereas the BOADICEA predictions are compatible with the observations. On the other hand the ROC curves indicate that BRCAPRO and BOADICEA both discriminate well between carriers and noncarriers. Thus, BRCAPRO and BOADICEA perform similarly in terms of ranking individuals by carrier probability, but the absolute carrier probabilities are only reliable for BOADICEA. To achieve comparable sensitivity and specificity, the cutoffs under the two models are therefore quite different. Users of the models must be aware of these issues when deciding whether to refer an individual for testing on the basis of carrier or mutation detection probabilities given by a particular model.

This is the first time the updated version of BOADICEA has been used to evaluate its prediction of mutation status in an independent data set. The version used here varies from the previous reported model [14] in that the model had been refitted using data from two additional population based studies $[44,45]$ and using a much larger number of $B R C A 1$ and $B R C A 2$ mutation-positive families [1]. In this respect the penetrance estimates in the latest version are more accurate. Other differences include the use of annual incidence rates as opposed to 5-year interval rates for both carriers and noncar- 
riers, the use of rates that are cohort specific, and incorporation of a polygenic component with a variance that decreases linearly with age. The familial relative risks predicted by this model are closer to the observed risks than those predicted by the previous version (Antoniou and coworkers, unpublished data). BRCA2 mutations (and, to a lesser extent, BRCA1 mutations) are associated with increased risks for male breast cancer, prostate cancer and pancreatic cancer, and several other cancers have been reported to occur at increased frequency in $B R C A 1$ or $B R C A 2$ carriers $[11,46,47]$. The risks for other cancers are not taken into account by the current version of BOADICEA. Incorporating such information into account is likely to result in more accurate carrier probabilities and in better discrimination between carriers and noncarriers, and we are currently extending the model to include such information.

Even though the BOADICEA model was developed using data from the UK, it seems to fit the occurrence of breast cancer in French-Canadian high-risk families. As demonstrated earlier, the penetrance estimates derived from these families are not significantly different from those used in BOADICEA. The good fit to these data suggests that the overall $B R C A 1$ and $B R C A 2$ allele frequencies are comparable to those in the UK population. This is supported by the fact that studies of prevalence of BRCA1 and BRCA2 mutations in French-Canadian patients with breast and ovarian cancer unselected for family history indicate similar prevalences of mutations as in the UK population and much lower than the prevalence of mutations among Ashkenazi Jewish women [44,45,48-50].

\section{Conclusion}

In the present study we estimated breast and ovarian cancer risks conferred by $B R C A 1$ and $B R C A 2$ mutations in FrenchCanadian families. These estimates are in line with previous ones but they are associated with very large confidence intervals. Additional families or further mutation testing in the families will be necessary to obtain more reliable estimates for this population. The results also suggest that the BOADICEA model of genetic susceptibility fits the data well; therefore, in the absence of reliable estimates, the penetrance functions used in this model can be employed for counselling BRCA1 and $B R C A 2$ mutation carriers in this population. Using information on all available relatives may improve individual mutation predictions as opposed to restricting information to second-degree relatives only.

\section{Competing interests}

The authors declare that they have no competing interests.

\section{Authors' contributions}

ACA was responsible for the analysis and data cleaning, and led the manuscript preparation. FD is a co-principal investigator in INHERIT BRCAs, initiated and coordinated collaborative efforts, was involved in the study design, and participated in the manuscript preparation. PS was responsible for data cleaning. JS was responsible for supervising mutation screening and laboratory work, initiated the study in high-risk FrenchCanadian families in 1996 (CBCRA grant), obtained further funding to start the international integrated research program INHERIT BRCAs, and was involved in revising the manuscript. DFE is a co-principal investigator of INHERIT BRCAs, and was involved in the development of the analytical design and in manuscript preparation.

\section{Acknowledgements}

The authors are indebted to the participants for their generosity and providing DNA samples. We would also like to thank Nathalie Bolduc,

Claire Brousseau, Dr Sylvie Délos, Marie-Andrée Lajoie, Pascale Léger, Hélène Malouin, Josée Rhéaume, Andrée McMillan and Tina Babineau for genetic counselling and clinical data management; and Dr Martine Dumont, Gilles Leblanc, Carolle Samson and Martine Tranchant for mutation screening and skilful technical assistance. We also appreciate the advice received from ethics committees. This work was supported by the Canadian Institutes of Health Research (CIHR) for the INHERIT BRCAs research program, Fonds de la Recherche en Santé du Québec (FRSQ)/Réseau de Médecine Génétique Appliquée (RMGA) and the Canadian Breast Cancer Research Alliance. ACA is funded by Cancer Research UK; FD is a recipient of a Research Career Award in the Health Sciences by IRSC/Rx\&D HRF; PS was funded by the INHERIT BRCAs program; JS is Chair holder of the Canada Research Chair in Oncogenetics; and DFE is a Principal Research Fellow of Cancer Research UK.

The INHERIT BRCAs members are as follows: Paul Bessette (Service de Gynécologie, Centre Hospitalier Universitaire de Sherbrooke, Fleurimont, Quebec, Canada); Peter Bridge (Molecular Diagnostic Laboratory, Alberta Children's Hospital, Calgary, Canada); Jocelyne Chiquette and Louise Provencher (Clinique des Maladies du sein DeschênesFabia, Hôpital du saint-Sacrement, Quebec, Canada); Rachel Laframboise (Service de Médecine Génétique, CHUQ, Pavillon CHUL, Quebec, Canada); Jean Lépine, Centre Hospitalier Regional de Rimouski, Rimouski, Canada); Bernard Lespérance and Roxane Pichette (Service d'hémato-oncologie, Hôpital du Sacré-Coeur, Montréal, Canada); Marie Plante (Service de Gynécologie, CHUQ, L'Hôtel-Dieu de Québec, Quebec, Canada); and Patricia Voyer (Clinique des maladies du sein, Carrefour de Santé de Jonquière, Jonquière, Canada).

\section{References}

1. Antoniou A, Pharoah PD, Narod S, Risch HA, Eyfjord JE, Hopper $\mathrm{JL}$, Loman $\mathrm{N}$, Olsson $\mathrm{H}$, Johannsson $\mathrm{O}$, Borg $\mathrm{A}$, et al:: Average risks of breast and ovarian cancer associated with BRCA1 or BRCA2 mutations detected in case Series unselected for family history: a combined analysis of $\mathbf{2 2}$ studies. Am J Hum Genet 2003, 72:1117-1130.

2. Easton DF, Ford D, Bishop DT: Breast and ovarian cancer incidence in BRCA1-mutation carriers. Breast Cancer Linkage Consortium. Am J Hum Genet 1995, 56:265-271.

3. Ford D, Easton DF, Stratton M, Narod S, Goldgar D, Devilee P, Bishop DT, Weber B, Lenoir G, Chang-Claude J, et al:: Genetic heterogeneity and penetrance analysis of the BRCA1 and BRCA2 genes in breast cancer families. The Breast Cancer Linkage Consortium. Am J Hum Genet 1998, 62:676-689.

4. Hopper JL, Southey MC, Dite GS, Jolley DJ, Giles GG, McCredie MR, Easton DF, Venter DJ: Population-based estimate of the average age-specific cumulative risk of breast cancer for a defined set of protein-truncating mutations in BRCA1 and BRCA2. Australian Breast Cancer Family Study. Cancer Epidemiol Biomarkers Prev 1999, 8:741-747. 
5. King MC, Marks JH, Mandell JB: Breast and ovarian cancer risks due to inherited mutations in BRCA1 and BRCA2. Science 2003, 302:643-646.

6. Risch HA, McLaughlin JR, Cole DE, Rosen B, Bradley L, Kwan E, Jack E, Vesprini DJ, Kuperstein G, Abrahamson JL, et al.: Prevalence and penetrance of germline BRCA1 and BRCA2 mutations in a population series of 649 women with ovarian cancer. Am J Hum Genet 2001, 68:700-710.

7. Satagopan JM, Offit K, Foulkes W, Robson ME, Wacholder S, Eng CM, Karp SE, Begg CB: The lifetime risks of breast cancer in Ashkenazi Jewish carriers of BRCA1 and BRCA2 mutations. Cancer Epidemiol Biomarkers Prev 2001, 10:467-473.

8. Satagopan JM, Boyd J, Kauff ND, Robson M, Scheuer L, Narod S, Offit K: Ovarian cancer risk in Ashkenazi Jewish carriers of BRCA1 and BRCA2 mutations. Clin Cancer Res 2002, 8:3776-3781.

9. Struewing JP, Hartge P, Wacholder S, Baker SM, Berlin M, McAdams M, Timmerman MM, Brody LC, Tucker MA: The risk of cancer associated with specific mutations of BRCA1 and BRCA2 among Ashkenazi Jews. N Engl J Med 1997, 336:1401-1408.

10. Thompson D, Easton D: Variation in cancer risks, by mutation position, in BRCA2 mutation carriers. Am J Hum Genet 2001, 68:410-419.

11. Thompson D, Easton D: Variation in BRCA1 cancer risks by mutation position. Cancer Epidemiol Biomarkers Prev 2002, 11:329-336.

12. Warner E, Foulkes W, Goodwin P, Meschino W, Blondal J, Paterson C, Ozcelik H, Goss P, Allingham-Hawkins D, Hamel N, et al.: Prevalence and penetrance of BRCA1 and BRCA2 gene mutations in unselected Ashkenazi Jewish women with breast cancer. J Natl Cancer Inst 1999, 91:1241-1247.

13. Thorlacius S, Struewing JP, Hartge P, Olafsdottir GH, Sigvaldason $\mathrm{H}$, Tryggvadottir L, Wacholder S, Tulinius H, Eyfjord JE: Population-based study of risk of breast cancer in carriers of BRCA2 mutation. Lancet 1998, 352:1337-1339.

14. Antoniou AC, Pharoah PP, Smith P, Easton DF: The BOADICEA model of genetic susceptibility to breast and ovarian cancer. Br J Cancer 2004, 91:1580-1590.

15. Claus EB, Risch N, Thompson WD: Autosomal dominant inheritance of early-onset breast cancer. Implications for risk prediction. Cancer 1994, 73:643-651.

16. Parmigiani G, Berry D, Aguilar O: Determining carrier probabilities for breast cancer-susceptibility genes BRCA1 and BRCA2. Am J Hum Genet 1998, 62:145-158.

17. Tyrer J, Duffy SW, Cuzick J: A breast cancer prediction model incorporating familial and personal risk factors. Stat Med 2004, 23:1111-1130.

18. Neuhausen S, Gilewski T, Norton L, Tran T, McGuire P, Swensen J, Hampel H, Borgen P, Brown K, Skolnick M, et al:: Recurrent BRCA2 6174delT mutations in Ashkenazi Jewish women affected by breast cancer. Nat Genet 1996, 13:126-128.

19. Struewing JP, Abeliovich D, Peretz T, Avishai N, Kaback MM, Collins FS, Brody LC: The carrier frequency of the BRCA1 185delAG mutation is approximately 1 percent in Ashkenazi Jewish individuals. Nat Genet 1995, 11:198-200.

20. Thorlacius S, Olafsdottir G, Tryggvadottir L, Neuhausen S, Jonasson JG, Tavtigian SV, Tulinius H, Ogmundsdottir HM, Eyfjord JE: A single BRCA2 mutation in male and female breast cancer families from Iceland with varied cancer phenotypes. Nat Genet 1996, 13:117-119.

21. Charbonneau $H$, Desjardins $B$, Légaré J, Denis $H$ : The population of the St. Lawrence valley, 1608-1760. In A Population History of North America Edited by: Haines MR, Steckel RH. New York: Cambridge University Press; 2000:99-142.

22. Scriver CR: Human genetics: lessons from Quebec populations. Annu Rev Genomics Hum Genet 2001, 2:69-101.

23. Oros KK, Ghadirian $P$, Greenwood CM, Perret C, Shen Z, Paredes Y, Arcand SL, Mes-Masson AM, Narod SA, Foulkes WD, et al.: Significant proportion of breast and/or ovarian cancer families of French Canadian descent harbor 1 of 5 BRCA1 and BRCA2 mutations. Int J Cancer 2004, 112:411-419.

24. Simard J, Dumont M, Moisan A-M, Durocher F, Laframboise R, Plante M, Chiquette J, Lesperance B, Pichette R, Lepine J: Molecular epidemiology of BRCA1 and BRCA2 mutations in French Canadian breast/ovarian families [abstract]. The 54th Annual Meeting of the American Society of Human Genetics, Toronto,
Ontario, Canada, October 26-30 2004 [http://www.ashg.org/ cgi-bin/ashg04s/ashg04]. (abstract number 480)

25. Vezina H, Durocher F, Houde L, Dumont M, Tranchant M, Gobeil L, Simard J, INHERIT BRCAs: Molecular and genealogical analyses of 8765 delAG, a BRCA2 founder mutation in high-risk French Canadian families [abstract]. The 54th Annual Meeting of the American Society of Human Genetics, Toronto, Ontario, Canada, October 26-30 2004 [http://www.ashg.org/cgi-bin/ ashg04s/ashg04]. (abstract number 1647)

26. Vezina $H$, Durocher $F$, Dumont $M$, Houde L, Szabo $C$, Tranchant $M$, Chiquette J, Plante M, Laframboise R, Lepine J, et al:: Molecular and genealogical characterization of the R1443X BRCA1 mutation in high-risk French-Canadian breast/ovarian cancer families. Hum Genet 2005, 117:119-132.

27. Apicella C, Andrews L, Hodgson SV, Fisher SA, Lewis CM, Solomon E, Tucker K, Friedlander M, Bankier A, Southey MC, et al.: Log odds of carrying an Ancestral Mutation in BRCA1 or BRCA2 for a Defined personal and family history in an Ashkenazi Jewish woman (LAMBDA). Breast Cancer Res 2003, 5:R206-R216.

28. Couch FJ, DeShano ML, Blackwood MA, Calzone K, Stopfer J, Campeau L, Ganguly A, Rebbeck T, Weber BL: BRCA1 mutations in women attending clinics that evaluate the risk of breast cancer. N Engl J Med 1997, 336:1409-1415.

29. Frank TS, Deffenbaugh AM, Reid JE, Hulick M, Ward BE, Lingenfelter B, Gumpper KL, Scholl T, Tavtigian SV, Pruss DR, et al.: Clinical characteristics of individuals with germline mutations in BRCA1 and BRCA2: analysis of 10,000 individuals. J Clin Oncol 2002, 20:1480-1490.

30. Berry DA, Parmigiani G, Sanchez J, Schildkraut J, Winer E: Probability of carrying a mutation of breast-ovarian cancer gene BRCA1 based on family history. I Natl Cancer Inst 1997 , 89:227-238.

31. Avard D, Bridge P, Bucci LM, Chiquette J, Dorval M, Durocher F, Easton D, Godard B, Goldgar D, Knoppers BM: Partnering in oncogenetics research - the INHERIT BRCAs experience: opportunities and challenges. Fam Cancer 2005 in press.

32. Simard J, Joly Y, Durocher F, Knoppers BM: Les enjeux éthiques du partage des résultats de recherche: L'expérience d'INHERIT BRCAs [in French]. In La Recherche en Génétique et en Génomique: Droits et Responsabilités. Trans: The ethical stakes of sharing research results: The INHERIT BRCAs experience in Research in Genetics and Genomics: Rights and Responsibilities Edited by: Philips-Nootens S, Godard B, Knoppers BM, Régnier M-H. Montréal: Les Éditions Thémis; 2005.

33. Jeanpierre M: A rapid method for the purification of DNA from blood. Nucleic Acids Res 1987, 15:9611.

34. Lange $K$, Weeks $D$, Boehnke M: Programs for pedigree analysis: MENDEL, FISHER, and dGENE. Genet Epidemiol 1988, 5:471-472.

35. Cannings $C$, Thompson EA: Ascertainment in the sequential sampling of pedigrees. Clin Genet 1977, 12:208-212.

36. Berry DA, Iversen ES Jr, Gudbjartsson DF, Hiller EH, Garber JE, Peshkin BN, Lerman C, Watson P, Lynch HT, Hilsenbeck SG, et al: BRCAPRO validation, sensitivity of genetic testing of BRCA1/BRCA2, and prevalence of other breast cancer susceptibility genes. J Clin Oncol 2002, 20:2701-2712.

37. BayesMendel [http://astor.som.jhmi.edu/BayesMendel/]

38. R-project [http://www.r-project.org/]

39. Brier GW: Verification of forecasts expressed in terms of probability. Monthly Weather Rev 1950, 78:1-3.

40. Spiegelhalter DJ: Probabilistic prediction in patient management and clinical trials. Stat Med 1986, 5:421-433.

41. Narod SA, Ford D, Devilee P, Barkardottir RB, Lynch HT, Smith SA, Ponder BA, Weber BL, Garber JE, Birch JM, et al:: An evaluation of genetic heterogeneity in 145 breast-ovarian cancer families. Breast Cancer Linkage Consortium. Am J Hum Genet 1995, 56:254-264.

42. Antoniou AC, Pharoah PD, Narod S, Risch HA, Eyfjord JE, Hopper $\mathrm{JL}$, Olsson $\mathrm{H}$, Johannsson $\mathrm{O}$, Borg $\mathrm{A}$, Pasini $\mathrm{B}$, et al:: Breast and ovarian cancer risks to carriers of the BRCA1 5382insC and 185delAG and BRCA2 6174delT mutations: a combined analysis of 22 population based studies. J Med Genet 2005, 42:602-603

43. Evans DG, Eccles DM, Rahman N, Young K, Bulman M, Amir E, Shenton A, Howell A, Lalloo F: A new scoring system for the chances of identifying a BRCA1/2 mutation outperforms exist- 
ing models including BRCAPRO. J Med Genet 2004, 41:474-480.

44. Lalloo F, Varley J, Ellis D, Moran A, O'Dair L, Pharoah P, Evans DG: Prediction of pathogenic mutations in patients with earlyonset breast cancer by family history. Lancet 2003, 361:1101-1102.

45. Peto J, Collins N, Barfoot R, Seal S, Warren W, Rahman N, Easton DF, Evans C, Deacon J, Stratton MR: Prevalence of BRCA1 and BRCA2 gene mutations in patients with early-onset breast cancer. J Nat/ Cancer Inst 1999, 91:943-949.

46. The Breast Cancer Linkage Consortium: Cancer risks in BRCA2 mutation carriers. J Natl Cancer Inst 1999, 91:1310-1316.

47. van Asperen CJ, Brohet RM, Meijers-Heijboer EJ, Hoogerbrugge N, Verhoef S, Vasen HF, Ausems MG, Menko FH, Gomez Garcia $\mathrm{EB}, \mathrm{Klijn} \mathrm{JG}$, et al:: Cancer risks in BRCA2 families: estimates for sites other than breast and ovary. J Med Genet 2005, 42:711-719.

48. Anglian Breast Cancer Study Group: Prevalence and penetrance of BRCA1 and BRCA2 mutations in a population-based series of breast cancer cases. Br J Cancer 2000, 83:1301-1308.

49. Chappuis PO, Hamel N Paradis AJ Deschenes J, Robidoux A Potvin C, Cantin J, Tonin P, Ghadirian P, Foulkes WD: Prevalence of founder BRCA1 and BRCA2 mutations in unselected French Canadian women with breast cancer. Clin Genet 2001, 59:418-423.

50. Tonin PM, Mes-Masson AM, Narod SA, Ghadirian P, Provencher D: Founder BRCA1 and BRCA2 mutations in French Canadian ovarian cancer cases unselected for family history. Clin Genet 1999, 55:318-324. 